\title{
A new glance at the chemosphere of macroalgal-bacterial interactions: In situ profiling of metabolites in symbiosis by mass spectrometry
}

\author{
Marine Vallet ${ }^{*}$, Filip Kaftan ${ }^{2}$, Veit Grabe ${ }^{3}$, Fatemeh Ghaderiardakani ${ }^{4}$, \\ Simona Fenizia ${ }^{4,5}$, Aleš Svatoš ${ }^{2}$, Georg Pohnert ${ }^{1,4,6}$ and Thomas Wichard ${ }^{*} 4$
}

\section{Full Research Paper}

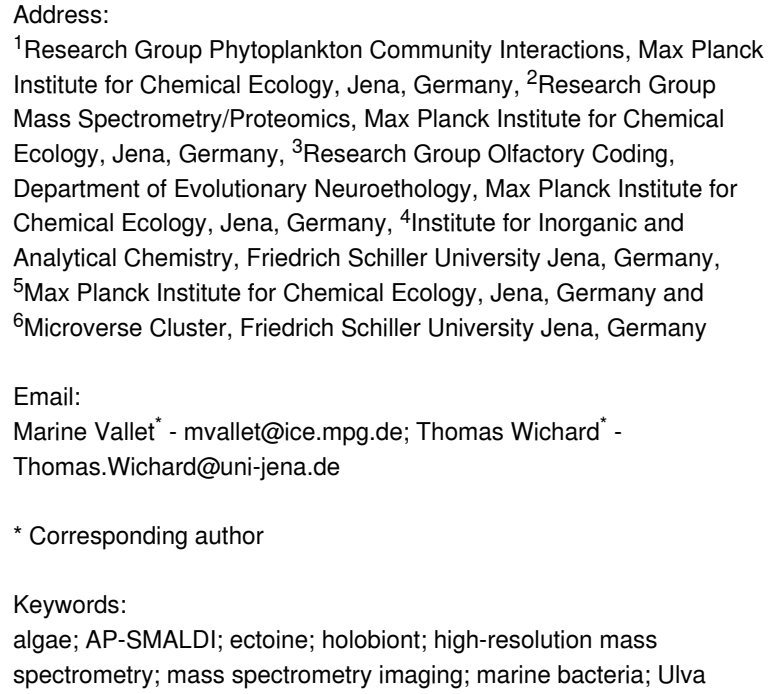

${ }^{1}$ Research Group Phytoplankton Community Interactions, Max Planck Institute for Chemical Ecology, Jena, Germany, ${ }^{2}$ Research Group Mass Spectrometry/Proteomics, Max Planck Institute for Chemical Ecology, Jena, Germany, ${ }^{3}$ Research Group Olfactory Coding, Department of Evolutionary Neuroethology, Max Planck Institute for Chemical Ecology, Jena, Germany, ${ }^{4}$ Institute for Inorganic and Analytical Chemistry, Friedrich Schiller University Jena, Germany, ${ }^{5}$ Max Planck Institute for Chemical Ecology, Jena, Germany and ${ }^{6}$ Microverse Cluster, Friedrich Schiller University Jena, Germany

Beilstein J. Org. Chem. 2021, 17, 1313-1322. https://doi.org/10.3762/bjoc.17.91

Received: 31 December 2020

Accepted: 28 April 2021

Published: 19 May 2021

This article is part of the thematic issue "Chemical ecology".

Guest Editor: C. Beemelmanns

(c) 2021 Vallet et al.; licensee Beilstein-Institut.

License and terms: see end of document.

\begin{abstract}
Symbiosis is a dominant form of life that has been observed numerous times in marine ecosystems. For example, macroalgae coexist with bacteria that produce factors that promote algal growth and morphogenesis. The green macroalga Ulva mutabilis (Chlorophyta) develops into a callus-like phenotype in the absence of its essential bacterial symbionts Roseovarius sp. MS2 and Maribacter sp. MS6. Spatially resolved studies are required to understand symbiont interactions at the microscale level. Therefore, we used mass spectrometry profiling and imaging techniques with high spatial resolution and sensitivity to gain a new perspective on the mutualistic interactions between bacteria and macroalgae. Using atmospheric pressure scanning microprobe matrix-assisted laser desorption/ionisation high-resolution mass spectrometry (AP-SMALDI-HRMS), low-molecular-weight polar compounds were identified by comparative metabolomics in the chemosphere of Ulva. Choline (2-hydroxy- $N, N, N$-trimethylethan-1-aminium) was only determined in the alga grown under axenic conditions, whereas ectoine (1,4,5,6-tetrahydro-2-methyl-4-pyrimidinecarboxylic acid) was found in bacterial presence. Ectoine was used as a metabolic marker for localisation studies of Roseovarius sp. within the tripartite community because it was produced exclusively by these bacteria. By combining confocal laser scanning microscopy (cLSM) and AP-SMALDI-HRMS, we proved that Roseovarius sp. MS2 settled mainly in the rhizoidal zone (holdfast) of $U$. mutabilis. Our findings provide the fundament to decipher bacterial symbioses with multicellular hosts in aquatic ecosystems
\end{abstract}


in an ecologically relevant context. As a versatile tool for microbiome research, the combined AP-SMALDI and cLSM imaging analysis with a resolution to level of a single bacterial cell can be easily applied to other microbial consortia and their hosts. The novelty of this contribution is the use of an in situ setup designed to avoid all types of external contamination and interferences while resolving spatial distributions of metabolites and identifying specific symbiotic bacteria.

\section{Introduction}

In intertidal zones with high temporal and spatial ecosystem variations, bacteria and macroalgae establish close mutualistic relationships, in which both gain reciprocal benefits forming an ecological unit (holobiont) [1-3]. Chemical exchange and physical proximity are the basis of this algae-bacterial mutualism [4], but little is known about the spatial distribution of the bacteria on the algal host and the locally released and exchanged compounds within the algal chemosphere [3]. Bacterial biofilms on macroalgae can be crucial for developing algae and their interactions with other marine organisms. The exchange of resources in this spatially limited region is of high interest for understanding the macroalgal-bacterial interactions. The chemosphere was proposed as a region that supports chemical mediator-based cross-kingdom interactions [3]. High-throughput sequencing analysis provides the abundance and composition of the bacterial community on macroalgal surfaces $[5,6]$. It does not reveal any information on the metabolically active bacteria and the spatial distribution of substances exchanged. While the study of bacterial symbiosis is often limited to either chemistry or microscopy work, recent functional and metabolomics methods are available to enable chemical imaging of specialised metabolites involved in host-bacteria interactions.

In our study, comparative metabolomics using atmospheric pressure scanning microprobe matrix-assisted laser desorption/ ionisation high-resolution mass spectrometry (AP-SMALDIHRMS) enables the identification of specialised metabolites of the marine macroalga Ulva mutabilis (Chlorophyta) and its associated essential bacteria, a model system for cross-kingdom interactions [7]. The method provides a tool to formulate hypotheses about metabolic processes in the phycosphere while preserving spatial structure. This novel depth of insight into a multicellular host and bacteria interactions can characterise natural products in symbiotic interactions.

Algal growth and morphogenesis-promoting factors (AGMPFs) are required for the development of the model organism U. mutabilis [7]. They are provided by a combination of two essential bacteria, Maribacter sp. MS6 and Roseovarius sp. MS2 forming a tripartite community [3,7,8] (see also Figure 1a and the Graphical Abstract). In turn, Roseovarius sp. benefits from the released photosynthate glycerol as a carbon source [9]. Axenic Ulva germ cells (i.e. gametes) develop into a callus-like phenotype composed of undifferentiated cells with malformed cell walls $[8,10]$. Up to now, the bacterial sesquiterpenoid thallusin, released by Maribacter spp. [11,12], is the only known AGMPF that induces morphogenesis such as rhizoid and cell-wall formation in Ulva spp. [11,12] or thallus development in Monostroma spp. [13]. The Roseovarius-factor that promotes cell division is still unknown $[3,8]$. Algal substances are released into the surrounding environment to attract epiphytic bacteria and initiate the cross-kingdom interaction [14,15]. Ulva attracts Roseovarius sp. MS2 through the sulphur-containing zwitterion dimethylsulphoniopropionate (DMSP), resulting in biofilm formation on the algal surrounding [9]. The bacterium subsequently uses the provided glycerol for growth and transforms DMSP into methanethiol and dimethyl sulphide [9].

The metabolic activities of marine bacteria and algae can be surveyed using mass spectrometry-based methods. For example, stable sulphur isotope $\left({ }^{34} \mathrm{~S}\right)$ labelled DMSP was used to track DMSP uptake and degradation by marine bacteria, and secondary ion mass spectrometry was applied to visualise it at the single-cell level [16]. The interaction between epibiotic bacteria on algal surfaces and their metabolic activities can be monitored in situ or using an imprinting method by desorption electrospray ionisation mass spectrometry $[17,18]$. In $U$. mutabilis gametophytes, matrix-assisted laser desorption ionisation mass spectrometry imaging (MALDI-MSI) was used to identify cell differentiation markers [19]. However, there has yet to be a thorough investigation of associated-mutualistic bacteria. MALDI-MSI has been shown to have high sensitivity and spatial resolution at the microscale in plant tissues, plankton, and other microbes [20,21].

The application of a MALDI matrix to a sample is an important part of the MALDI-MSI experiment. MALDI-MS can be used to identify proteins and metabolic signatures [22-24] from bacteria and microalgae, as well as biofilms [25]. The primary function of the applied matrix is to improve the quality of the MS spectra, particularly the signal intensities of the compounds of interest. In some cases, the matrix might also work in opposition to this premise, suppressing desired ions. Then, matrix-free approaches such as LDI-HRMS can overcome this limiting phenomenon and have been applied for species-level microalgal identification based on metabolic profile fingerprint matching [26-28]. 
Our research combines cutting-edge laser scanning microscopy and high-resolution mass spectrometry to uncover Ulva/bacteria interactions and specialised metabolites at the microscale level. In this study, we demonstrate that the chemosphere of $U$. mutabilis changes depending on the presence or absence of the bacterial symbionts (Roseovarius sp. MS2 and Maribacter sp. MS6). As a result, specific metabolic markers can be used to identify bacteria in the vicinity of $U$. mutabilis. We used an untargeted comparative metabolomics approach that also provides micrometre-resolved MS imaging data through AP-SMALDI-HRMS. Two sample preparations, matrix-free LDI and MALDI, were performed to increase the range of metabolites recovered with this type of ionisation. We identified significant metabolites that define the host-bacteria interactions based on spectral similarity with standards. Using combined imaging mass spectrometry and confocal laser scanning microscopy, we then linked the chemical and microscopic observations that characterise the symbiotic association (cLSM).

\section{Results and Discussion Comparative metabolomics using AP-SMALDI-HRMS identifies metabolites in axenic algae and those present during macroalgal-bacterial symbiosis}

Axenic gametes of $U$. mutabilis (phenotype slender) were allowed to settle onto glass plates in Petri dishes filled with growth medium. In the absence of the symbionts, the axenic gametes developed into undifferentiated cells known as the callus-like form $[8,29]$. In the second set of samples, algae were inoculated with the two marine bacteria, Roseovarius sp. MS2 and Maribacter sp. MS6, developing into a phenotype composed of bilayer cells and organised tissues, as previously reported [8]. The algal germlings incubated with the marine bacteria showed a rhizoidal zone that serves for substrate attachment and a thallus zone. From apex to rhizoid, Ulva germlings had an average length of 50 to $150 \mu \mathrm{m}$ after three weeks of growth. The samples were recovered, dried on tissue, and for MALDI, immediately covered with 2,5-dihydroxybenzoic acid (DHB) applied by spraying. We targeted either specialised tissues (rhizoidal zone versus thallus) or the whole alga germlings (axenic callus versus alga in symbiosis) using a mounted AP-SMALDI camera (Figure 1a). The metabolic profiles of tissue and whole alga were obtained from callus or alga in symbiosis using AP-SMALDI-HRMS with the two sample preparations, either with matrix deposition (MALDIHRMS) or matrix-free analysis (LDI-HRMS) (Figure 1a and b). The data matrix was generated by processing the raw spectra, and the data tables produced were from 1534 to 4986 features $(\mathrm{m} / \mathrm{z})$ (Figure 1b and Table S1 in Supporting Information
File 1). The principal component analysis (PCA) visualised differences between metabolic profiles of axenic algae, algae in symbiosis, and specialised tissues (thallus, rhizoidal zone), analysed either with LDI or MALDI-HRMS. The metabolic profiles of axenic algae and algae in symbiosis were significantly different, while tissue-specialised metabolomes were less differentiated in the PCA score plots (Figure 1b). Significant features in the loading plots were listed in a heatmap to compare their relative abundance of intensities averaged per sample class (Figure 1c). Among the statistically significant features in all datasets (Table S1, Supporting Information File 1), six metabolites were identified, which were annotated using spectral similarity with analytical standards. For example, the features $\mathrm{m} / \mathrm{z} 104.1064$ and $\mathrm{m} / \mathrm{z} 143.0815$ were selected among the significant markers of the MALDI-HRMS profiling of axenic algae and the rhizoid tissue (whole alga profiling) of $U$. mutabilis grown with the marine symbiotic bacteria, respectively (Figure 1c). The heatmap shows the complementarities of both methods, LDI or MALDI-HRMS, as the significant features $\mathrm{m} / \mathrm{z} 104.1064$ and $\mathrm{m} / \mathrm{z} 143.0815$ have only been detected by one of the two methods.

\section{Identification of metabolites in Ulva-bacteria symbiosis}

To identify the selected markers found by the comparative metabolomics study, we searched several mass spectra libraries, including METLIN, and determined the chemical formula based on exact mass. We also used spectral similarity matching of data acquired from analytical standards. Choline was identified from the molecular peak $\mathrm{m} / \mathrm{z} 104.1064$ for $[\mathrm{M}]^{+}$(calculated $\mathrm{m} / \mathrm{z}$ as $104.1069 \pm 4.8 \mathrm{ppm}$ for $\mathrm{C}_{5} \mathrm{H}_{14} \mathrm{NO}$ ) in the profiles of axenic U. mutabilis (Figure 2a). This small polar metabolite was linked to the metabolic homeostasis of Ulva lactuca during tidal cycles [30]. Choline is the precursor of the membrane constituent phosphatidylcholine [31]. We inferred that the accumulation of choline in axenic $U$. mutabilis germlings might correlate with the absence of the key bacterial morphogen thallusin, which induces cell wall and rhizoid formation. The accompanying formation of cell wall protrusions might disrupt the cell membrane arrangement indicated by choline accumulation. Screening the tripartite community Ulva-Roseovarius-Maribacter identified ectoine as a metabolic marker of the rhizoidal zone (Figure $2 b$ ). The molecular formula $\mathrm{C}_{6} \mathrm{H}_{10} \mathrm{~N}_{2} \mathrm{O}_{2}$ was deduced from the molecular peak at $m / z 143.0817$ for $[\mathrm{M}+\mathrm{H}]^{+}( \pm 1.4 \mathrm{ppm})$ and $m / z 165.0636$ for $[\mathrm{M}+\mathrm{Na}]^{+}( \pm 1.2 \mathrm{ppm})$ detected in the AP-SMALDI-HRMS profiles of the standard and rhizoid tissue of $U$. mutabilis in symbiosis with the marine bacteria. To separate algal and bacterial metabolism, single colonies of Roseovarius sp. MS2 and Maribacter sp. MS6 were deposited onto glass slides and analysed with AP-SMALDI-HRMS/MS. Using spectral similarity matching based on the fragmentation pattern 
a

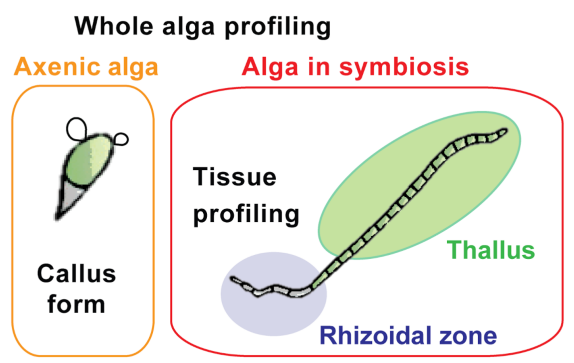

C Whole alga profiling

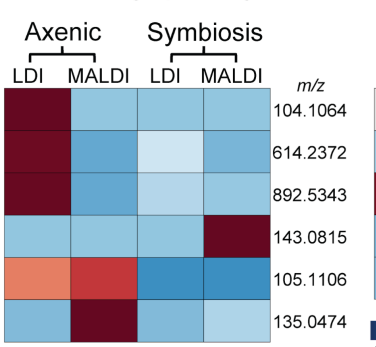

Tissue profiling

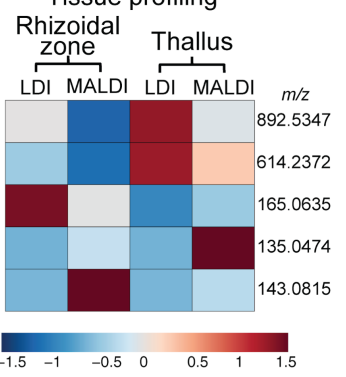

b

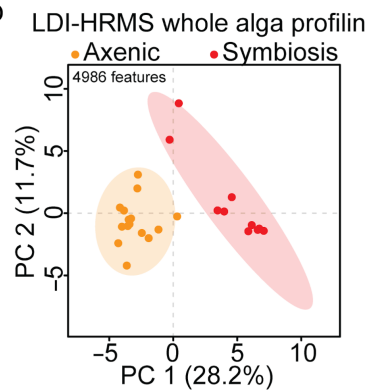

MALDI-HRMS whole alga profiling

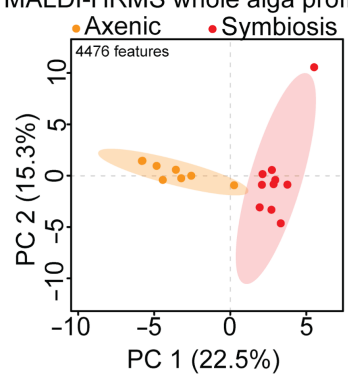

LDI-HRMS tissue profiling

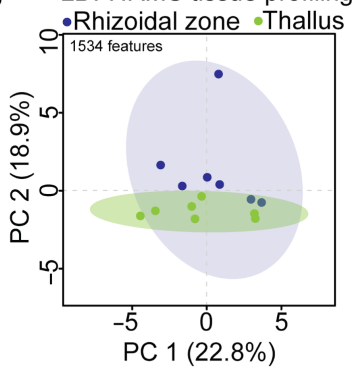

PC $1(22.8 \%)$

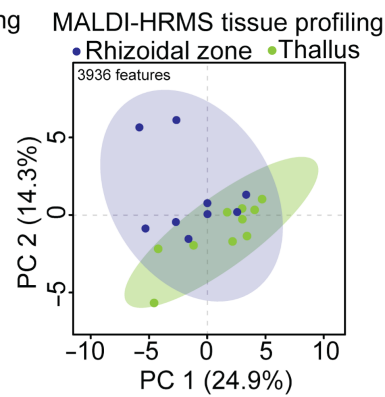

Figure 1: Untargeted comparative metabolomics using AP-SMALDI-HRMS highlighted metabolites involved in Ulva-bacteria symbiosis. a) The study looked at axenic algae with cell wall protrusions, the whole algae, and specific tissues with bacterial symbionts. b) The profiles of axenic alga ("axenic") were contrasted with alga with bacterial symbionts ("symbiosis") in the PCA score plots for LDI and MALDI-HRMS. The ellipses represent the $95 \%$ confidence region. c) The significant features $(\mathrm{m} / \mathrm{z}$ ) characterising axenic algae, algae in symbiosis, or differentiated tissues (blades/thalli, rhizoids) are represented in a heatmap with their relative abundance. The colour scale represents the averaged TIC normalised intensities per sample class (red colour for high intensity, blue for low intensity).

obtained from AP-SMALDI-HRMS/MS experiments, we proved that the bacterial symbiont Roseovarius sp. MS2 produces ectoine (Figure 2c). This observation supports earlier assumptions that the rhizoidal zone is mainly colonised by Roseovarius sp. MS2 [8,29].

Ectoine is a known osmoprotectant produced by marine bacteria and phytoplankton with high concentrations during saline stress conditions [32]. It has not yet been described in the Ulva-bacteria symbiosis. Not all essential genes for ectoine biosynthesis reported by [33] were found in the U. mutabilis genome [34], providing further support for the bacterial origin of ectoine. Homologs of EctA (UM017_0070.1, E value 0.34), EctB (UM084_0040.1, E value < 0.0001) that provide the central intermediate $N$-acetyl-2,4-diaminobutyrate and EctD (UM025_0127.1, E value 0.094) an ectoine hydroxylase could be identified. However, a homolog gene for EctC (ectoine synthase) is missing in the U. mutabilis genome. In addition, despite the low E value of EctB, the reciprocal NCBI-blast search against the anoxygenic photosynthetic halophile and ectoine-producing bacterium Halorhodospira halochloris [35] did not confirm the presence of the sequence in the algal genome. Therefore, it is unlikely that the alga produces ectoine. In summary, ectoine is indicative of Roseovarius sp. MS2 in the tripartite community and can serve for localisation studies.

\section{Localisation of bacterial symbionts of Ulva mutabilis using fluorescence microscopy and imaging mass spectrometry}

Based on the above results, we combined LDI-MS imaging mass spectrometry and cLSM using a non-specific fluorescence labelling probe to visualise the bacterial cells living in symbiosis with $U$. mutabilis. Following a one-month incubation in clean cuvette slides placed in Petri dishes filled with medium, axenic and bacteria-inoculated $U$. mutabilis germlings were stained with SYBR Gold, a sensitive probe forming a complex with DNA with high fluorescence quantum yield [36]. In the axenic callus-like form, the nuclei of algal cells and the bacterial cells accumulated around the rhizoidal tissue and exhibited the specific fluorescence after SYBR Gold staining (Figure 3a) as previously described [8,37]. These findings indicated that bacteria are associated with their algal host during symbiosis.

In parallel, we visualised the metabolites produced by the biofilm formed around $U$. mutabilis by imaging analysis with AP-SMALDI-HRMS. Three replicates each of the axenic algae, algae in symbiosis, germlings, and bacterial cells in monocultures were imaged after matrix deposition by AP-SMALDIHRMS over a centimetre-scaled area (Figure $3 b$ ). The algal pigment chlorophyll was localised with the algal tissues (Figure $3 \mathrm{~b}$ and Figure S1 in Supporting Information File 1). Even though 
a
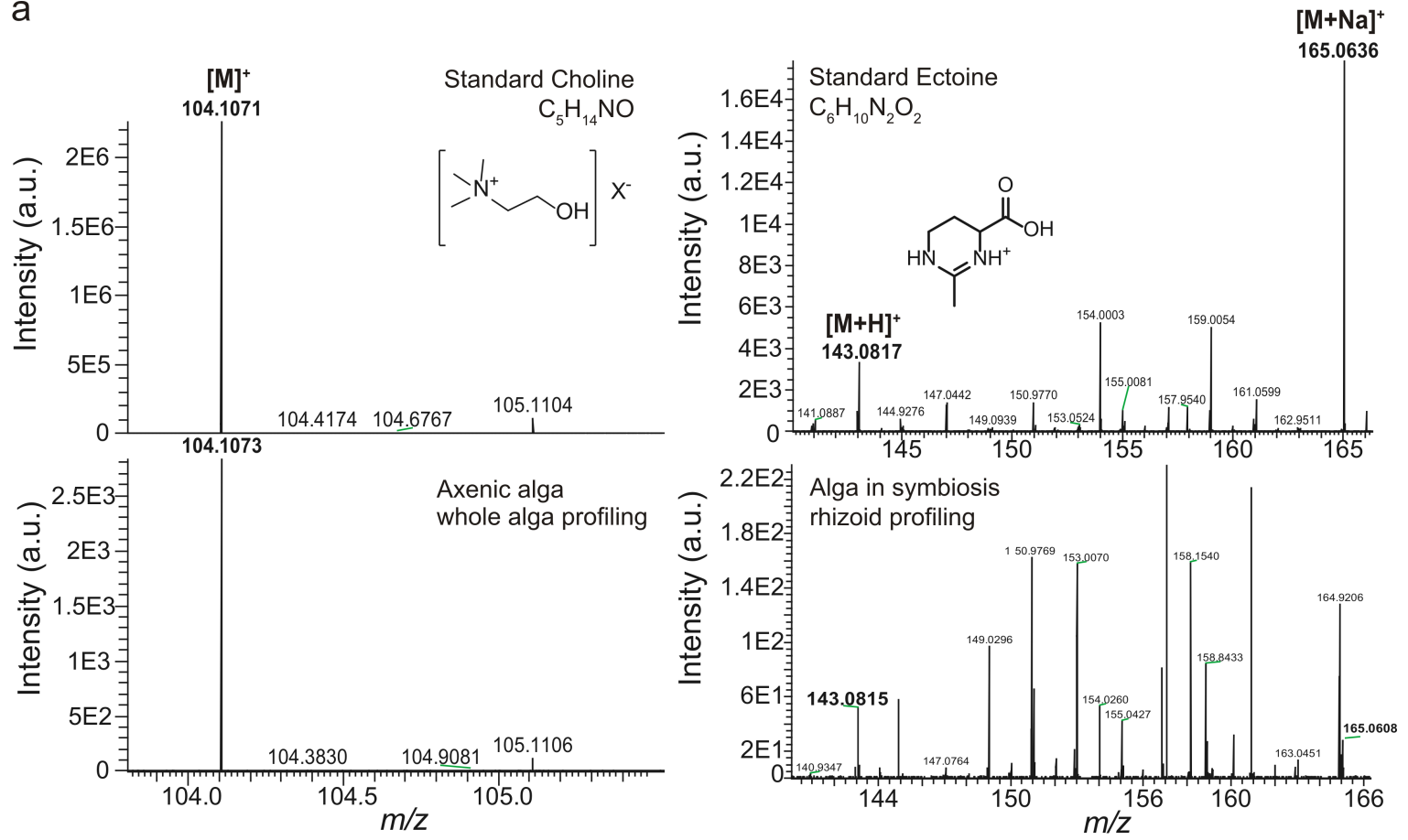

b

Ectoine $\mathrm{m} / \mathrm{z} 143.0815$

C
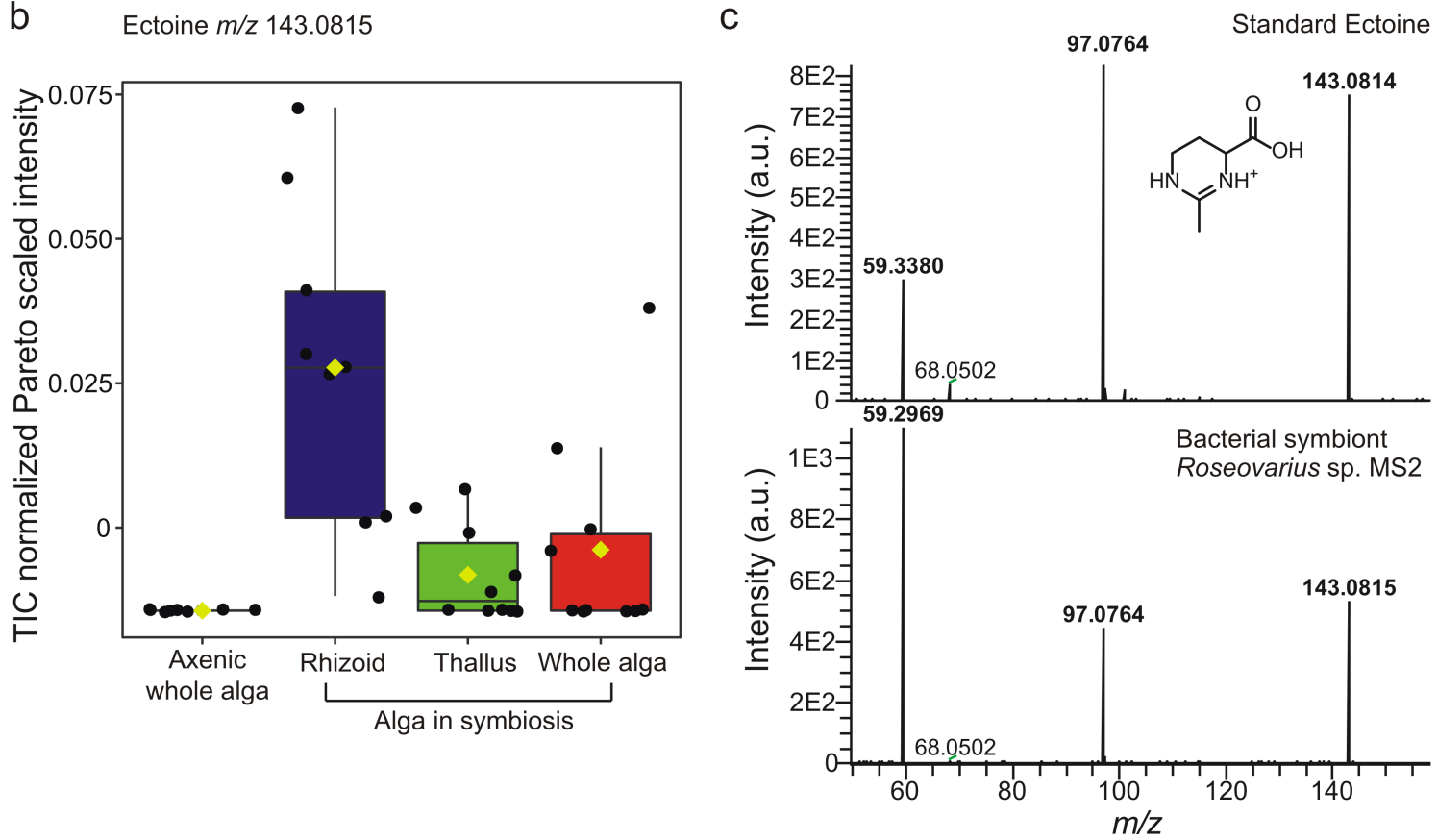

Figure 2: Identification of significant features associated with axenic or bacterial symbiont-associated alga Ulva mutabilis (phenotype slender). a) The structural determination was achieved by spectral matching with the analytical standards using AP-SMALDI-HRMS. b) Relative amounts of ectoine $\left(\mathrm{m} / \mathrm{z} 143.0815\right.$ for $\left.[\mathrm{M}+\mathrm{H}]^{+}\right)$were determined by AP-SMALDI-HRMS measurements to compare different tissues: axenic and algae in symbiosis. Oneway ANOVA with a Fisher HSD post hoc test found choline to be significant in profiles of axenic algae $(F=42, P$-value $<0.0001)$ and ectoine in profiles of rhizoidal zones of algae in symbiosis $(F=4, P$-value $<0.005)$ (colour code with reference to Figure $1 \mathrm{a}) . \mathrm{c})$ Ectoine $(\mathrm{m} / \mathrm{z} 143.0815$ for $[\mathrm{M}+\mathrm{H}]^{+}$, precursor ion) was identified in a single colony of the bacterial symbiont Roseovarius sp. MS2 using AP-SMALDI-HRMS/MS analysis.

most of the seawater media was removed from the Ulva samples during sample preparation, crystallisation of seawater salts on the sample surface occurred. The size of the crystals and their distribution within an imaged area were examined using a digital microscope and found to be homogeneous and consistent across the samples and experiments. As a result, the ion 
a

Cytochemical staining with confocal laser scanning microscopy

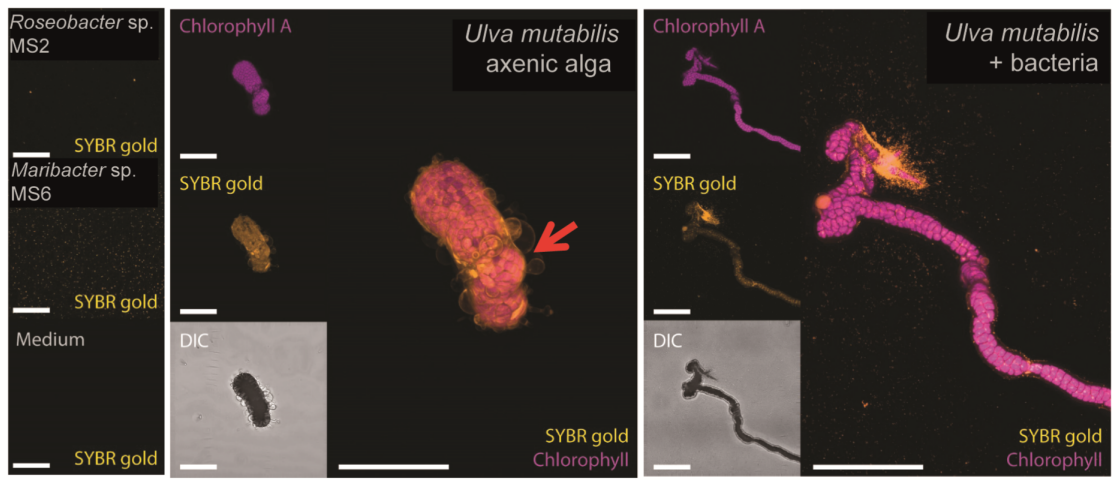

b AP-SMALDI-HRMS

Symbiont-free alga

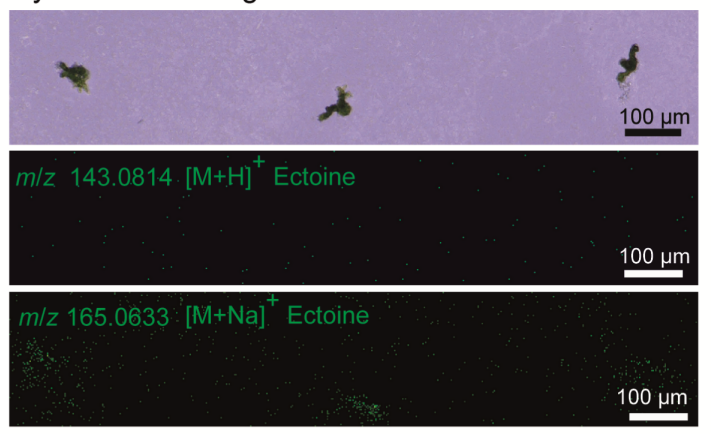

Roseovarius sp. MS2 Alga in symbiosis with bacteria

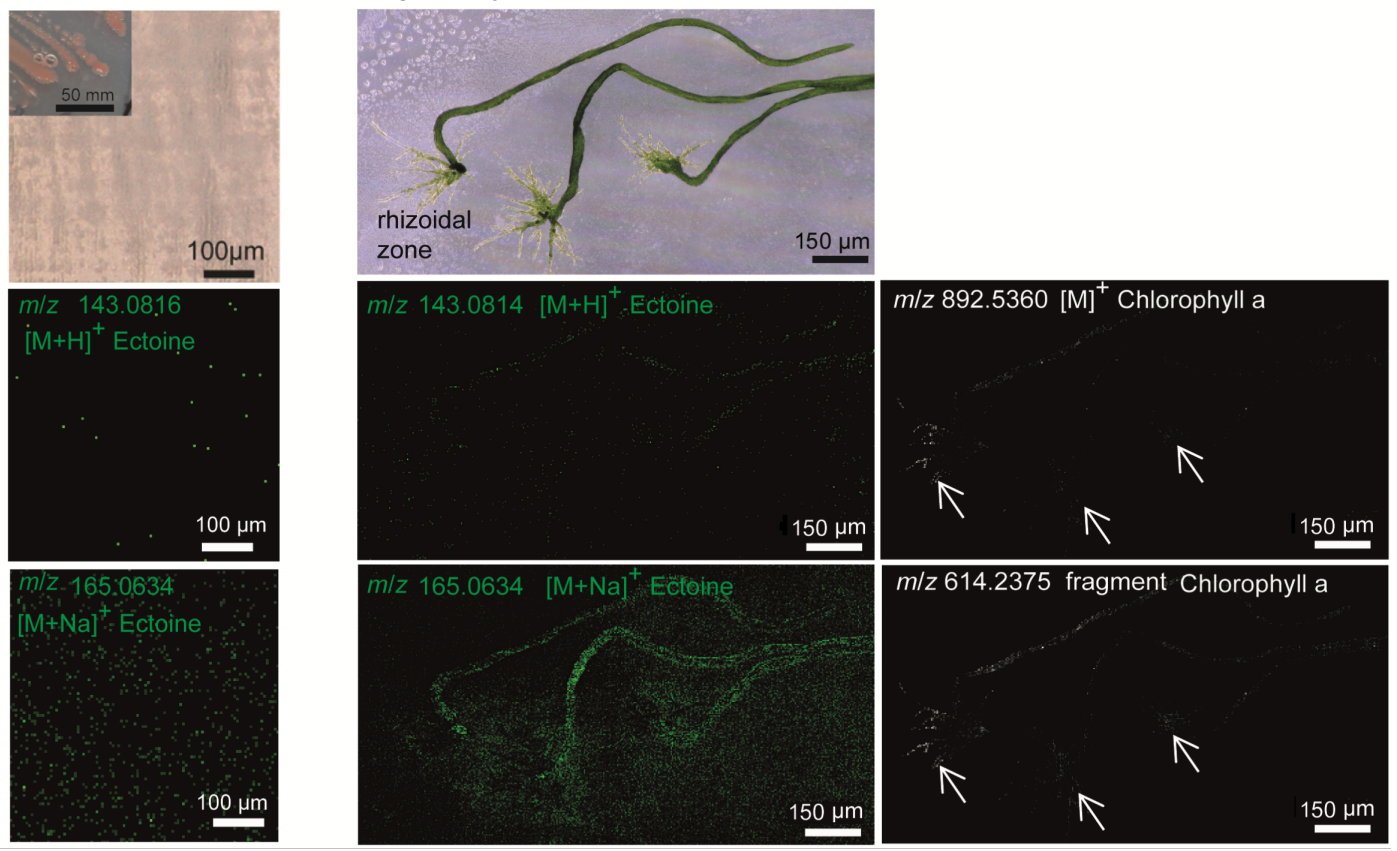

Figure 3: Visualisation of algae Ulva mutabilis grown under axenic conditions or with bacterial symbionts Roseovarius sp. MS2 and Maribacter sp. MS6. a) Images acquired after nucleic acid staining with SYBR gold and with confocal laser scanning microscopy. The protrusion of alga grown without bacterial symbiont is highlighted (red arrow). DIC: differential interference microscopy. b) The images show ectoine spatial localisation and thus the presence of Roseovarius sp. ( $\mathrm{m} / \mathrm{z} 143.0814$ for $[\mathrm{M}+\mathrm{H}]^{+}, \mathrm{m} / \mathrm{z} 165.0633$ for $[\mathrm{M}+\mathrm{Na}]^{+}$, shown in green) as well as chlorophyll $(\mathrm{m} / \mathrm{z} 892.5360 \mathrm{for}$ $[\mathrm{M}+\mathrm{H}]^{+}, \mathrm{m} / \mathrm{z} 614.2375$ fragment shown in white). These metabolite traces are visible in axenic algae, symbiotic algae, and cell cultures of bacteria Roseovarius sp. MS2. White arrows indicate the rhizoidal zones. 
suppression effect caused by the presence of seawater crystals on the Ulva samples and surroundings was consistent across all measurements (Supporting Information File 1, Figures S1 and S2).

Ectoine was detected in both profiling and imaging MS spectra as the $[\mathrm{M}+\mathrm{Na}]^{+}$adduct at $\mathrm{m} / \mathrm{z} 165.0633$. Ectoine was mainly found around the rhizoid in elevated amounts. Thus, Roseovarius sp. MS2 became visible in the rhizoidal zone and on the thallus due to the exclusive production of ectoine within the tripartite community (Figure 3b). AP-SMALDI-HRMS studies extended to the entire clade of motile Rhodobacteraceae will reveal other characteristic metabolites of the Ulva-bacteria interactions. Those species attracted by $U$. mutabilis (e.g., through DMSP) that use the provided photosynthates [9], will preferentially succeed the previously described competitive colonisations of Ulva spp. [38,39]. Also, related species of Roseovarius sp. MS2 can often release unknown AGMPFs $[29,40]$, which further foster the bacterial-algal interactions. As more species-specific metabolic markers become available, AP-SMALDI imaging will be a powerful tool to track these dynamic microbial colonisation processes using the $U$. mutabilis model system with a designed microbiome.

\section{Conclusion}

Metabolic profiling of whole alga and specialised tissues conducted with AP-SMALDI-HRMS enabled identifying specific metabolites in host-bacteria symbiosis. We report the first identification of choline and ectoine as markers of symbiont-free $U$. mutabilis and rhizoid tissue of algae in symbiosis with bacteria. We visualised the rhizoidal zone formed by the bacterial symbionts using chemical staining, confocal laser scanning microscopy, and imaging mass spectrometry. Notably, ectoine was used as a metabolic marker to identify bacteria in the biofilm associated with $U$. mutabilis and the algal surface. Visualising the spatial distribution of epiphytic bacteria in the phycosphere will contribute to the general understanding of the chemically mediated cross-kingdom interactions. The combined AP-SMALDI and CLSM imaging with resolution down to the level of a single bacterial cell introduced here can be applied to other microbial consortia and their hosts and will be instrumental for microbiome research.

\section{Experimental Biological experiments and imaging microscopy}

The laboratory strains of $U$. mutabilis $(\mathrm{sl}-\mathrm{G}[\mathrm{mt}+])$ are direct descendants of the original isolates collected by B. Føyn in Portugal (Ria Formosa) in 1958 [8]. This strain is used as a model organism in cross-kingdom interactions $[7,34,37]$ and cultivated under standardised conditions [41,42]. Ulva strains are available from the corresponding author (Thomas Wichard, Friedrich-Schiller-Universität Jena, Germany).

Gametogenesis of U. mutabilis was induced by chopping harvested algal tissue, and released gametes were purified from accompanying bacteria according to the protocol of Wichard and Oertel (2010) [41]. The strains Roseovarius sp. MS2 (Genbank EU359909) and Maribacter sp. MS6 (Genbank EU359911) were originally isolated from U. mutabilis [8] and were cultivated in Marine Broth medium (Roth, Germany) at $20{ }^{\circ} \mathrm{C}$. Ulva gametes were either grown axenically or inoculated with the bacteria (final optical density $\mathrm{OD}_{620}=0.001$ ). All algae were cultivated in Ulva culture medium (UCM) [43] at $18{ }^{\circ} \mathrm{C}$ with the illumination of about $60 \mu \mathrm{mol}$ photons $\mathrm{m}^{-2} \mathrm{~s}^{-1}$ under a 17:7 light/dark regime. Axenic Ulva gametes deposited on cleaned glass slides and inoculated with bacteria MS2/MS6 were prepared following the procedure for in situ MS imaging described by Kessler et al. [19]. Briefly, algal gametes were inoculated to $10 \mathrm{~mL}$ medium in $9 \mathrm{~cm}$ diameter sterile Petri dishes with a clean and autoclaved glass slide $(25 \mathrm{~mm} \times 75 \mathrm{~mm}$ ) with cavities (Paul Marienfeld, Germany) on the bottom; samples were incubated for one month at $18{ }^{\circ} \mathrm{C}$ in static conditions. An inverted microscope was used to monitor the algal growth. Transmitted light microscopy pictures were obtained using a Keyence BHX-500 digital microscope. Samples were recovered with pliers and fixed with glutaraldehyde $1 \%$ (Merck), stained with SYBR Gold (1\% in DMSO, Invitrogen, Thermo Fisher); a cover slide was added, followed by incubation in the dark at $15{ }^{\circ} \mathrm{C}$ for $15 \mathrm{~min}$. Cavity slides were spotted with $100 \mu \mathrm{L}$ of SYBR Gold or unstained bacterial monoculture (Roseovarius sp MS2 or Maribacter sp. MS6) to use them as controls. Fluorescence images $(1024 \times 1024)$ were acquired using a Zeiss cLSM 880 (Carl Zeiss AG, Oberkochen, Germany) with a Plan-Apochromat $20 \times 0.8$ and $488 \mathrm{~nm}$ Argon-laser excitation (5\% transmission). Emission wavelengths for SYBR Gold (490-650 nm) and chlorophyll A (653-735 nm) were separated via the spectral detection unit. Transmitted light was detected by the transmitted light-PMT. The effect of an additional quick washing step was tested by gently adding $100 \mu \mathrm{L}$ of sterile MQ water for two seconds. The controls consisted of bacteria grown for one week in monoculture in $40 \mathrm{~mL}$ of marine broth medium and the axenic medium with fixative and stain. All the experiments with glass slides were performed in biological triplicates.

\section{Genome analysis}

To identify the putative biosynthetic gene cluster (ect gene cluster) in U. mutabilis [34], the algal genome was searched for the gene ectoine hydroxylase (ectD) and also for a specialised aspartokinase (ask_ect). Aspartokinase (Ask), along with 
L-aspartate- $\beta$-semialdehyde-dehydrogenase (Asd), provides the precursor L-ASA for ectoine biosynthesis $[33,44,45]$. Homologs of the enzymes of the ectoine pathway from Halorhodospira halochloris were identified by BLAST searches of the $U$. mutabilis genome at ORCAE using default parameters (https://bioinformatics.psb.ugent.be/orcae/overview/Ulvmu).

\section{AP-SMALDI-HRMS metabolic profiling and imaging}

All standards and Ulva samples were analysed via AP-SMALDI (AP-SMALDI10, TransMit, Germany) ion source equipped with a UV (337 nm) nitrogen laser (LTB MNL-106, LTB, Germany) coupled to a high-resolution mass spectrometer Q-Exactive Plus (Thermo Fisher Scientific, Bremen, Germany) Glass slides with one month-grown algal gametophytes were gently recovered from a Petri dish filled with UCM using a sterile tweezer and dipped for one second in sterile ultrapure water to remove the excess salts before metabolic profiling. When algae were investigated directly on a glass slide before in situ MS imaging, blotting paper was used to remove sea water (see also Supporting Information File 1). The desired area of a glass slide covered with algal individuals was first marked, photographed, and finally fixed on the AP-SMALDI metal target.

AP-SMALDI profiling and imaging experiments unless otherwise stated were enhanced by a 2,5-dihydroxybenzoic acid (DHB) MALDI matrix. A methanolic solution of the DHB matrix at a concentration of $4 \mathrm{mg} \mathrm{mL}^{-1}$ was applied onto a sample via SunChrom MALDI spotter (SunChrom $\mathrm{GmbH}$, Germany). The spraying method was optimised using the following parameters: line distance $2 \mathrm{~mm}$, spraying speed $800 \mathrm{~mm} \mathrm{~min}^{-1}$ with 5 seconds drying time, and matrix solution flow rate in 4 cycles from $10 \mu \mathrm{L}$ up to $30 \mu \mathrm{L} \mathrm{min}^{-1}$. Solvents used in this study were all LCMS analytical grade. 2,5Dihydroxybenzoic acid with a purity of above $98 \%$ and high purity MS-grade methanol were purchased from Sigma-Aldrich (Germany).

All Ulva samples were imaged in the positive ion mode using a step size of $5 \mu \mathrm{m}$ and with the number of laser shots per spot set to 30 (approximately $1.2 \mu \mathrm{J}$ shot $^{-1}$ ) within the laser frequency of $60 \mathrm{~Hz}$. MS spectra were acquired in a mass range from $\mathrm{m} / \mathrm{z} 100$ to $\mathrm{m} / \mathrm{z} 1000$ with a resolving power of 280000 . Pseudo ion intensity maps of selected $\mathrm{m} / \mathrm{z}$ values were generated using the Mirion V3 software package with an $\mathrm{m} / \mathrm{z}$ width of $0.01 \mathrm{u}$.

In the profiling mode, the single Ulva individuals were targeted visually and ablated with a laser spot size of approximately $10 \mu \mathrm{m}$ in positive and negative polarity in a mass range from $\mathrm{m} / \mathrm{z} 100$ to $\mathrm{m} / \mathrm{z} 1000$. The other parameters stayed like for the
MSI mode. In profiling, the same area of the rhizoid and the tip of the thallus of different individuals were analysed by laser ablation over one-minute time acquisition. Axenic and alga in symbiosis germlings were profiled with a UV laser along a longitudinal axis to investigate the effect of bacteria on metabolism changes in $U$. mutabilis.

The size of the sample groups analysed by AP-SMALDIHRMS in profiling mode was $n=10$ for thallus tissue, $n=9$ for rhizoid tissue, $n=8$ for axenic callus, and $n=10$ for alga in symbiosis. Matrix-free experiments (LDI-HRMS) were performed in profiling mode under the same experimental conditions as the AP-SMALDI-HRMS. The size of the sample groups was defined as follows: $n=6$ for rhizoid, $n=7$ for thallus and whole alga profiling, $n=10$ for alga in symbiosis, and $n=15$ for axenic alga.

The metabolic profiles of nutrient media were obtained by analysing $30 \mu \mathrm{L}$ deposited onto cleaned glass slides and following the same protocol used for the Ulva samples. In the late exponential stage, bacterial monoculture was recovered from agar plates with a $10 \mu \mathrm{L}$ loop and diluted in $100 \mu \mathrm{L}$ of sterile water. Five microliters of the solution were spotted onto a glass slide and analysed in AP-SMALDI-HRMS mode in positive and negative polarity.

The data acquired in MSI mode were collected with Xcalibur software version 2.8 SP1 Build 2806 (Thermo Fisher Scientific, Germany) while the acquisition of spatial scans, pre-defined in the $x$ - and $y$-direction as rectangular sample regions, was controlled by the MCP (Master Control Program, TransMIT $\mathrm{GmbH}$, Giessen, Germany). The raw data acquired in profiling mode were visualised in Thermo Xcalibur ${ }^{\mathrm{TM}}$ version 3.0.63 (Thermo Fisher Scientific, Germany) and then converted to netCDF format using the Thermo File Converter tool. Data preprocessing was performed to extract the intensities in each profile, excluding the features of the nutrient medium using a script adapted from the MALDIquand package [46]. Spectra were de-noised with a signal-to-noise ratio of 5. Normalisation was done based on total ion current (TIC) recommended for MALDI-MS analysis [47]. All spectra, images, R data, scripts, and results from the statistical analysis were uploaded and are freely accessible in the Max Planck repository Edmond (https:// dx.doi.org/10.17617/3.4v).

\section{Significant features analysis and metabolite identification}

Data analysis was conducted in MetaboAnalyst 4.0 [48] to perform univariate and multivariate statistical tests and find significant differences in intensities and the presence or absence of metabolites in the samples. Pareto scaling and cube root trans- 
formation were conducted to normalise the datasets before the multivariate statistics. PCA highlighted the metabolic differences between axenic and alga in symbiosis and between thallus and rhizoid tissues. Significant features were searched in the PCA loading plots and also in the pattern hunter plots obtained from a correlation analysis based on the Pearson correlation coefficient R. A one-way ANOVA with Fisher's LSD post hoc test $(P$-value $<0.05)$ was performed, and the relative amounts of the significant features were displayed as a boxplot. The selected significant features were further searched in the raw HRMS profiles to identify those with the reliable isotopic pattern assigned to a metabolite. The $m / z$ values were searched in the METLIN database, using a mass deviation equal to or lower than five ppm, which suggested several known natural products such as ectoine [49].

To confirm the identity of the significant features, mass spectral information was compared with analytical standards analysed with the AP-SMALDI-HRMS (DMSP, chlorophyll-a, ectoine, choline). MS/MS experiments were performed with AP-SMALDI-HRMS to match the fragmentation pattern between the standard ectoine and bacteria monoculture profile. Fragmentation spectra of ectoine were acquired from the bacterial isolate Roseovarius sp. MS2 and an ectoine standard. To perform a measurement, $4 \mu \mathrm{L}$ of ectoine at concentration $50 \mu \mathrm{M}$ was pipetted onto a clean glass slide (washed with $\mathrm{dH}_{2} \mathrm{O}$, acetone) and overlaid with $2 \mu \mathrm{L}$ of a methanolic solution of the DHB matrix at a concentration of $4 \mathrm{mg} \mathrm{mL}^{-1}$. For a bacterial isolate, the sample was prepared from one colony smeared onto a glass slide and covered with the DHB matrix, following the standard ectoine procedure. Samples were analysed in positive ion mode, with the number of laser shots per spot set to 30 (approximately $1.2 \mu \mathrm{J} \operatorname{shot}^{-1}$ ). All-ion fragmentation (AIF) mode was set as follows: molecular ion of ectoine at $\mathrm{m} / \mathrm{z} 143.1$; isolation window $m / z \pm 0.2 ; 45 \mathrm{NCE}$. The peak resolution was set at 280000 , and the mass range was set from $\mathrm{m} / \mathrm{z} 50$ to $\mathrm{m} / \mathrm{z} 300$

\section{Supporting Information}

\section{Supporting Information File 1}

Details on sample preparation and additional figures.

[https://www.beilstein-journals.org/bjoc/content/

supplementary/1860-5397-17-91-S1.pdf]

\section{Funding}

SF was funded by the International Max Planck Research School Exploration of Ecological Interactions with Molecular Techniques. This work was supported by an MPG Fellowship awarded to GP and by the Deutsche Forschungsgemeinschaft through Grant No. SFB 1127/2 ChemBioSys-239748522 (GP, TW) and within the framework of the priority program (SPP 1158) "Antarctic Research with comparative investigations in Arctic ice areas" under the project number \#424256657 (FG, TW).

\section{ORCID ${ }^{\circledR}$ iDs}

Marine Vallet - https://orcid.org/0000-0002-6878-0459 Filip Kaftan - https://orcid.org/0000-0002-5851-945X Veit Grabe - https://orcid.org/0000-0002-0736-2771 Fatemeh Ghaderiardakani - https://orcid.org/0000-0003-3497-8421 Simona Fenizia - https://orcid.org/0000-0002-3592-9368 Aleš Svatoš - https://orcid.org/0000-0003-1032-7288 Georg Pohnert - https://orcid.org/0000-0003-2351-6336 Thomas Wichard - https://orcid.org/0000-0003-0061-4160

\section{References}

1. Ramanan, R.; Kim, B.-H.; Cho, D.-H.; Oh, H.-M.; Kim, H.-S. Biotechnol. Adv. 2016, 34, 14-29. doi:10.1016/j.biotechadv.2015.12.003

2. Singh, R. P.; Reddy, C. R. K. FEMS Microbiol. Ecol. 2014, 88, 213-230. doi:10.1111/1574-6941.12297

3. Wichard, T.; Beemelmanns, C. J. Chem. Ecol. 2018, 44, 1008-1021. doi:10.1007/s10886-018-1004-7

4. Croft, M. T.; Lawrence, A. D.; Raux-Deery, E.; Warren, M. J.; Smith, A. G. Nature 2005, 438, 90-93. doi:10.1038/nature04056

5. Selvarajan, R.; Sibanda, T.; Venkatachalam, S.; Ogola, H. J. O.; Christopher Obieze, C.; Msagati, T. A. Sci. Rep. 2019, 9, 19835 doi:10.1038/s41598-019-56269-2

6. Burke, C.; Thomas, T.; Lewis, M.; Steinberg, P.; Kjelleberg, S. ISME J. 2011, 5, 590-600. doi:10.1038/ismej.2010.164

7. Wichard, T.; Charrier, B.; Mineur, F.; Bothwell, J. H.; Clerck, O. D.; Coates, J. C. Front. Plant Sci. 2015, 6, 72. doi:10.3389/fpls.2015.00072

8. Spoerner, M.; Wichard, T.; Bachhuber, T.; Stratmann, J.; Oertel, W. J. Phycol. 2012, 48, 1433-1447. doi:10.1111/j.1529-8817.2012.01231.x

9. Kessler, R. W.; Weiss, A.; Kuegler, S.; Hermes, C.; Wichard, T. Mol. Ecol. 2018, 27, 1808-1819. doi:10.1111/mec.14472

10. Alsufyani, T.; Weiss, A.; Wichard, T. Mar. Drugs 2017, 15, 14. doi:10.3390/md15010014

11. Alsufyani, T.; Califano, G.; Deicke, M.; Grueneberg, J.; Weiss, A.; Engelen, A. H.; Kwantes, M.; Mohr, J. F.; Ulrich, J. F.; Wichard, T. J. Exp. Bot. 2020, 71, 3340-3349. doi:10.1093/jxb/eraa066

12. Weiss, A.; Costa, R.; Wichard, T. Bot. Mar. 2017, 60, 197-206. doi:10.1515/bot-2016-0083

13. Matsuo, Y.; Imagawa, H.; Nishizawa, M.; Shizuri, Y. Science 2005, 307, 1598. doi:10.1126/science. 1105486

14. Bell, W.; Mitchell, R. Biol. Bull. (Woods Hole, MA, U. S.) 1972, 143 , 265-277. doi:10.2307/1540052

15. Joint, I.; Tait, K.; Callow, M. E.; Callow, J. A.; Milton, D.; Williams, P.; Cámara, M. Science 2002, 298, 1207. doi:10.1126/science.1077075

16. Raina, J.-B.; Clode, P. L.; Cheong, S.; Bougoure, J.; Kilburn, M. R.; Reeder, A.; Forêt, S.; Stat, M.; Beltran, V.; Thomas-Hall, P.; Tapiolas, D.; Motti, C. M.; Gong, B.; Pernice, M.; Marjo, C. E.; Seymour, J. R.; Willis, B. L.; Bourne, D. G. eLife 2017, 6, e23008. 
17. Lane, A. L.; Nyadong, L.; Galhena, A. S.; Shearer, T. L.; Stout, E. P.; Parry, R. M.; Kwasnik, M.; Wang, M. D.; Hay, M. E.; Fernandez, F. M.; Kubanek, J. Proc. Natl. Acad. Sci. U. S. A. 2009, 106, 7314-7319. doi:10.1073/pnas.0812020106

18. Parrot, D.; Blümel, M.; Utermann, C.; Chianese, G.; Krause, S.; Kovalev, A.; Gorb, S. N.; Tasdemir, D. Sci. Rep. 2019, 9, 1061. doi:10.1038/s41598-018-37914-8

19. Kessler, R. W.; Crecelius, A. C.; Schubert, U. S.; Wichard, T. Anal. Bioanal. Chem. 2017, 409, 4893-4903. doi:10.1007/s00216-017-0430-7

20. Mandal, A.; Singha, M.; Addy, P. S.; Basak, A. Mass Spectrom. Rev. 2019, 38, 3-21. doi:10.1002/mas.21545

21. Hansen, R. L.; Lee, Y. J. Chem. Rec. 2018, 18, 65-77. doi:10.1002/tcr.201700027

22. Yang, Y.; Lin, Y.; Qiao, L. Anal. Chem. (Washington, DC, U. S.) 2018, 90, 10400-10408. doi:10.1021/acs.analchem.8b02258

23. Barbano, D.; Diaz, R.; Zhang, L.; Sandrin, T.; Gerken, H.; Dempster, T. PLoS One 2015, 10, e0135337. doi:10.1371/journal.pone.0135337

24. Sandrin, T. R.; Goldstein, J. E.; Schumaker, S. Mass Spectrom. Rev. 2013, 32, 188-217. doi:10.1002/mas.21359

25. Dunham, S. J. B.; Ellis, J. F.; Li, B.; Sweedler, J. V. Acc. Chem. Res. 2017, 50, 96-104. doi:10.1021/acs.accounts.6b00503

26. Peterson, D. S. Mass Spectrom. Rev. 2007, 26, 19-34. doi:10.1002/mas.20104

27. Baumeister, T. U. H.; Vallet, M.; Kaftan, F.; Guillou, L.; Svatoš, A.; Pohnert, G. Metabolomics 2020, 16, 28. doi:10.1007/s11306-020-1646-7

28. Baumeister, T. U. H.; Vallet, M.; Kaftan, F.; Svatoš, A.; Pohnert, G. Front. Plant Sci. 2019, 10, 172. doi:10.3389/fpls.2019.00172

29. Ghaderiardakani, F.; Coates, J. C.; Wichard, T. FEMS Microbiol. Ecol. 2017, 93, fix094. doi:10.1093/femsec/fix094

30. Gupta, V.; Kushwaha, H. R. Sci. Rep. 2017, 7, 16430. doi:10.1038/s41598-017-15994-2

31. Zeisel, S. H. Phosphatidylcholine: endogenous precursor of choline. In Lecithin: Technological, Biological, and Therapeutic Aspects; Hanin, I.; Ansell, G. B., Eds.; Advances in Behavioral Biology, Vol. 33; Springer US: Boston, MA, USA, 1987; pp 107-120. doi:10.1007/978-1-4757-1933-8_11

32. Fenizia, S.; Thume, K.; Wirgenings, M.; Pohnert, G. Mar. Drugs 2020, 18, 42. doi: $10.3390 / \mathrm{md} 18010042$

33. Richter, A. A.; Mais, C.-N.; Czech, L.; Geyer, K.; Hoeppner, A.; Smits, S. H. J.; Erb, T. J.; Bange, G.; Bremer, E. Front. Microbiol. 2019, 10, 2811. doi:10.3389/fmicb.2019.02811

34. De Clerck, O.; Kao, S.-M.; Bogaert, K. A.; Blomme, J.; Foflonker, F.; Kwantes, M.; Vancaester, E.; Vanderstraeten, L.; Aydogdu, E.; Boesger, J.; Califano, G.; Charrier, B.; Clewes, R.; Del Cortona, A.; D'Hondt, S.; Fernandez-Pozo, N.; Gachon, C. M.; Hanikenne, M.; Lattermann, L.; Leliaert, F.; Liu, X.; Maggs, C. A.; Popper, Z. A.; Raven, J. A.; Van Bel, M.; Wilhelmsson, P. K. I.; Bhattacharya, D.; Coates, J. C.; Rensing, S. A.; Van Der Straeten, D.; Vardi, A.; Sterck, L.; Vandepoele, K.; Van de Peer, Y.; Wichard, T.; Bothwell, J. H. Curr. Biol. 2018, 28, 2921-2933.e5. doi:10.1016/j.cub.2018.08.015

35. Schuh, W.; Puff, H.; Galinski, E. A.; Trüper, H. G. Z. Naturforsch., C: J. Biosci. 1985, 40, 780-784. doi:10.1515/znc-1985-11-1206

36. Tuma, R. S.; Beaudet, M. P.; Jin, X.; Jones, L. J.; Cheung, C.-Y.; Yue, S.; Singer, V. L. Anal. Biochem. 1999, 268, 278-288. doi:10.1006/abio.1998.3067

37. Wichard, T. Front. Plant Sci. 2015, 6, 86. doi:10.3389/fpls.2015.00086
38. Frank, O.; Michael, V.; Päuker, O.; Boedeker, C.; Jogler, C.; Rohde, M.; Petersen, J. Syst. Appl. Microbiol. 2015, 38, 120-127. doi:10.1016/j.syapm.2014.12.001

39. Rao, D.; Webb, J. S.; Kjelleberg, S. Appl. Environ. Microbiol. 2006, 72 , 5547-5555. doi:10.1128/aem.00449-06

40. Grueneberg, J.; Engelen, A. H.; Costa, R.; Wichard, T. PLoS One 2016, 11, e0146307. doi:10.1371/journal.pone.0146307

41. Wichard, T.; Oertel, W. J. Phycol. 2010, 46, 248-259. doi:10.1111/j.1529-8817.2010.00816.x

42. Nahor, O.; Morales-Reyes, C. F.; Califano, G.; Wichard, T.; Golberg, A.; Israel, Á. Bot. Mar. 2021, 64, 83-92. doi:10.1515/bot-2020-0050

43. Stratmann, J.; Paputsoglu, G.; Oertel, W. J. Phycol. 1996, 32, 1009-1021. doi:10.1111/j.0022-3646.1996.01009.x

44. Peters, P.; Galinski, E. A.; Trüper, H. G. FEMS Microbiol. Lett. 1990, 71, 157-162. doi:10.1111/j.1574-6968.1990.tb03815.x

45. Reshetnikov, A. S.; Khmelenina, V. N.; Trotsenko, Y. A. Arch. Microbiol. 2006, 184, 286-297. doi:10.1007/s00203-005-0042-z

46. Gibb, S.; Strimmer, K. Mass spectrometry analysis using MALDlquant. In Statistical Analysis of Proteomics, Metabolomics, and Lipidomics Data Using Mass Spectrometry; Datta, S.; Mertens, B. J. A., Eds.; Springer International Publishing: Cham, Switzerland, 2017; pp 101-124. doi:10.1007/978-3-319-45809-0_6

47. Emara, S.; Amer, S.; Ali, A.; Abouleila, Y.; Oga, A.; Masujima, T. Single-Cell Metabolomics. In Metabolomics: From Fundamentals to Clinical Applications; Sussulini, A., Ed.; Advances in Experimental Medicine and Biology, Vol. 965; Springer International Publishing: Cham, Switzerland, 2017; pp 323-343. doi:10.1007/978-3-319-47656-8_13

48. Chong, J.; Soufan, O.; Li, C.; Caraus, I.; Li, S.; Bourque, G.; Wishart, D. S.; Xia, J. Nucleic Acids Res. 2018, 46, W486-W494. doi:10.1093/nar/gky310

49. Guijas, C.; Montenegro-Burke, J. R.; Domingo-Almenara, X.; Palermo, A.; Warth, B.; Hermann, G.; Koellensperger, G.; Huan, T.; Uritboonthai, W.; Aisporna, A. E.; Wolan, D. W.; Spilker, M. E.; Benton, H. P.; Siuzdak, G. Anal. Chem. (Washington, DC, U. S.) 2018, 90, 3156-3164. doi:10.1021/acs.analchem.7b04424

\section{License and Terms}

This is an Open Access article under the terms of the Creative Commons Attribution License (https://creativecommons.org/licenses/by/4.0). Please note that the reuse, redistribution and reproduction in particular requires that the author(s) and source are credited and that individual graphics may be subject to special legal provisions.

The license is subject to the Beilstein Journal of Organic Chemistry terms and conditions: (https://www.beilstein-journals.org/bjoc/terms)

The definitive version of this article is the electronic one which can be found at: https://doi.org/10.3762/bjoc. 17.91 